\title{
COMPARATIVE STUDY BETWEEN SPONTANEOUS FUNGAL PERITONITIS (SFP) AND SPONTANEOUS BACTERIAL PERITONITIS (SBP) IN PATIENTS WITH END STAGE LIVER DISEASE (ESLD)
}

\author{
By
Mohamed El-Nadry, Abdallah H. El-Shahat, Mohamed Abo-Ghabsha*, and Amr G. Basiouny \\ Hepato-Gastroenterology and Clinical-Pathology* Departments, Faculty of Medicine, Al- \\ Azhar University, Cairo, Egypt \\ Corresponding author: Amr G. Basiouny \\ Email: miroman1a@ hotmail.com, Phone number: 01145421992-01279449175
}

\begin{abstract}
Background: Bacterial infections in end stage liver disease are common and associated with increased mortality. Although extensive research has elucidated the impact of bacterial infections as the major precipitating event leads to increased frequency of liver-related complications and mortality in these patients.
\end{abstract}

Objective: Evaluating the clinical and laboratory characters, risk factors, and outcome of fungal and bacterial peritonitis in cirrhotic patients with end stage liver disease (ESLD).

Patients and Methods: This cross sctional study enrolled 60 patients with liver cirrhosis and ascites. Fifty patients were culture-positive spontaneous peritonitis, including 12 with spontaneous fungal peritonitis (SFP), and 38 culture-positive spontaneous bacterial peritonitis (SBP), and 10 patients without clinical or laboratory evidence of peritonitis as a control group, during the study period, between 1st February 2018 and 30th May 2019. We compared the clinical, laboratory findings, Child-Pugh scores, model for end stage liver disease (MELD) score, risk factors, and mortality rates between patients with spontaneous peritonitis associated with fungal culture-positive ascites, and those with spontaneous peritonitis associated with bacterial culture-positive ascites.

Results: Patients of the current study were critically ill. The mean duration of ESLD in the studied patients was $4.75 \pm 1.8$ year, 57 patients $(95.0 \%)$ were Child score $\mathrm{C}$, and 3 patients $(5 \%)$ were Child score $\mathrm{B}$. The mean MELD score was $23.32 \pm 5.49$. All patients with evidence of peritonitis were Child $\mathrm{C}$, and mean MELD scores were $22.6 \pm 5.7$ and $26.1 \pm 4.5$ in SBP and SFP groups respectively. Jaundice, GI bleeding and hepatic encephalopathy were significantly for clinical presentation and predictors of mortality in SFP group compared to SBP and control group. Lower levels of hemoglobin ( $\mathrm{Hb})$, S. albumin and platelets count and increased level of total leukocytic count (TLC), international normalized ratio (INR), and bilirubin were significantly higher in SFP group compared to SBP and control group.

Duration of ESLD and hospital admission was significant in SFP compared to SBP and control group. HCC was evident in SFP group (66.7\%) that was highly significant in comparison to SBP (28.9\%), and control group (20\%). Overall mortality rate among the studied groups was $45 \%$, the mortality rate was significantly increased in SFP group $(75 \%)$ compared to SBP $(42.1 \%)$, and control group (20\%). The mean MELD score significantly increased in non-survival group compared to survival group . The duration of ESLD significantly increased in non-survival group compared to survival group.

Conclusion: Prolonged and severe underlying liver disease with a high Child- Pugh or MELD score, renal impairment, HCC, and onset of severe sepsis have been reported as risk factors in increased mortality in 
patients with SFP than in SBP. In SFP, mortality was associated not only with the severity of the underlying liver disease, but also with delay in diagnosis and initiation of antifungal therapy.

Keywords: fungal infection, liver cirrhosis, Spontaneous fungal peritonitis.

\section{INTRODUCTION}

Patients with liver cirrhosis (LC) are at a high risk of developing bacterial and fungal infections such as spontaneous bacterial peritonitis (SBP) or spontaneous fungal peritonitis (SFP), which can be life-threatening in this population. Various mechanisms predispose patients with LC to infections. Impairment of immune function has been well documented and is characterized by multiple immune deficiencies, involving not only local liver damage but also deficiencies in systemic innate and acquired immunity (Albillos et al, 2014). Increased gastrointestinal (GI) permeability and pathological bacterial translocation are considered key factors leading to increased infection susceptibility in LC (Bellot et al, 2013).

The clinical features and prognosis of SBP, the most common type of bacterial infectious disease affecting patients with, have been well documented. Furthermore, in bacterascites, a subtype of SBP, bacteria may be cleared naturally from ascitic fluid. Accordingly, the need for antibacterial therapies in such cases remains uncertain. In contrast, the features of SFP (or fungiascites) in patients with liver cirrhosis remain less well-known, and few studies have compared SFP and SBP or, more generally, spontaneous peritonitis caused by fungi (SFP or fungiascites) with those caused by bacteria (SBP or bacterascites) (Shizuma, 2018). To address this differences the study was conducted on 60 patients with Chronic liver disease to estimate Clinical characteristics, risk factors, and prognosis of spontaneous fungal peritonitis (SFP) in comparison to spontaneous bacterial peritonitis (SBP) in patients with end stage liver disease (ESLD).

The aim of this work was to evaluate clinical and laboratory characters, risk factors, and outcome of fungal and bacterial peritonitis in cirrhotic patients with ESLD.

\section{PATIENTS AND METHODS}

For this study, we enrolled 60 patients with chronic liver disease admitted to the Hepato-Gastroenterology and Infectious diseases Departments, Al-Azhar University, and Al-Helal Hospital, Cairo, Egypt, from 1st February 2018 and 30th May 2019. Fifty patients were classified into 2 groups: SFP Group included 12 patients with positive culture for fungal peritonitis; SBP group included 38 patients with positive culture for bacterial peritonitis, in addition to control group which included 10 patients with end stage liver disease. All patients who met the diagnostic criteria of culture-positive spontaneous peritonitis were selected and included in this study. The diagnostic criteria of culture positive spontaneous peritonitis were as follows: Ascitic fluid polymorphonuclear leukocyte (PMN) count $>250$ cells $/ \mathrm{mm} 3$, positive ascitic fluid culture and absence of intraabdominal sources of infection or inflammation proven by abdominal imaging. Patient's sero-positive for human immunodeficiency virus (HIV) and patients undergoing continuous 
ambulatory peritoneal dialysis were excluded from the study.

All patients were subjected to full history and clinical examination. Routine laboratory evaluation and imaging study were done. All patients were subjected to diagnostic paracentesis immediately after admission or upon presentation of signs and/or symptoms suggestive of peritonitis. Ten milliliters of ascetic fluid were collected at the bedside and inoculated into aerobic and anaerobic blood culture bottles. Bacterial culture was performed manually using MacConkey and blood agar plate. Fungal culture was performed in the same manner using Emmons Sabouraud dextrose agar (ESDA). The ascetic fluid PMN count was determined simultaneously, and empirical antibiotics were administered immediately after diagnostic paracentesis. The ascetic fluid PMN count and cultures were determined $48 \mathrm{~h}$ after the start of treatment for all SFP and SBP patients. The criteria used to consider the antibiotic therapy successful were negative results of ascites and blood cultures; and a sustained decrease in the ascitic PMN count to $<50 \%$ of the initial value $48 \mathrm{~h}$ after the initiation of antibiotics.

All patients involved in the current study were informed about the nature and details of the current work and a written consent was obtained for each one.

\section{Statistical analysis:}

The collected data were revised, coded, tabulated and introduced to a PC using Statistical package for Social Science (SPSS 20). Data was presented and suitable analysis was done according to the type of data obtained for each parameter.

\section{i. Descriptive statistics:}

1. Mean, Standard deviation $( \pm$ SD) and range for parametric numerical data, while Median and Interquartile range (IQR) for non-parametric numerical data.

2. Frequency and percentage of nonnumerical data.

\section{ii. Analytical statistics:}

1. Student $t$ test was used to assess the statistical significance of the difference between two study group means.

2. ANOVA test was used to assess the statistical significance of the difference between more than two study group means.

3. Post Hoc Test was used for comparisons of all possible pairs of group means.

4. Chi-Square test was used to examine the relationship between two qualitative variables.

5. Fisher's exact test was used to examine the relationship between two qualitative variables when the expected count is less than 5 in more than $20 \%$ of cells.

6. Logistic regression was useful in the prediction of the presence or absence of an outcome based on a set of independent variables. It is similar to a linear regression model but is suited when the dependent variable is qualitative (categorical). 


\section{RESULTS}

The present study was conducted on 60 patients with chronic liver diseases admitted to the Tropical Medicine Department, Al-Azhar University, and AlHelal Hospital Cairo, Egypt, from 1st February 2018 and 30th May 2019. Fifty patients were classified into 2 groups: SFP group included 12 patients with positive culture for fungal peritonitis, and SBP group included 38 patients with positive culture for bacterial peritonitis, in addition to control group which included 10 patients with end stage liver disease matched with the previous two groups with no evidence of peritonitis, which were admitted for different reasons.

Male gender was significantly higher in control group than SBP and SFP group, and female gender was not represented in the control group, and was significantly higher in SFP group. There was no significant difference regarding to age between the studied groups (Table 1).

Table (1): Comparison between the demographic data among the studied groups

\begin{tabular}{|c|c|c|c|c|c|c|c|c|}
\hline \multirow{2}{*}{\multicolumn{2}{|c|}{ Parameters }} & \multicolumn{2}{|c|}{$\begin{array}{c}\text { Control } \\
\text { No. }=10\end{array}$} & \multicolumn{2}{|c|}{$\begin{array}{c}\text { SBP } \\
\text { No. }=38\end{array}$} & \multicolumn{2}{|c|}{$\begin{array}{c}\text { SFP } \\
\text { No. }=12\end{array}$} & \multirow{2}{*}{$\begin{array}{c}\begin{array}{c}\text { Fisher } \\
\text { exact test }\end{array} \\
p \text { value }\end{array}$} \\
\hline & & $\mathrm{N}$ & $\%$ & $\mathrm{~N}$ & $\%$ & $\mathrm{~N}$ & $\%$ & \\
\hline \multirow{2}{*}{$\operatorname{sex}$} & Male & 10 & $100.0 \%$ & 29 & $76.3 \%$ & 6 & $50.0 \%$ & \multirow{2}{*}{0.028} \\
\hline & Female & 0 & $0.0 \%$ & 9 & $23.7 \%$ & 6 & $50.0 \%$ & \\
\hline \multirow{2}{*}{\multicolumn{2}{|c|}{ Age (years) }} & Mean & SD & $\begin{array}{c}\text { Mea } \\
\mathrm{n}\end{array}$ & SD & Mean & SD & ANOVA \\
\hline & & 54.6 & 11.2 & 57.7 & 6.7 & 58.5 & 7.5 & 0.458 \\
\hline
\end{tabular}

There was no significant difference between the studied groups regarding to the Child score, but there were significant differences regarding to overall mortality.
The highest mortality rate was among the SFP group $9 / 12$ patients $(75.0 \%)$ versus $16(42.1 \%)$ and $2(20.0 \%)$ in SBP and control group respectively (Table 2 ).

Table (2): Outcome of patient's post-treatment with anti-fungal therapy

\begin{tabular}{|c|c|c|c|c|c|c|c|c|}
\hline \multirow{2}{*}{\multicolumn{2}{|c|}{ Parameters Groups }} & \multicolumn{2}{|c|}{$\begin{array}{c}\text { Control } \\
\text { No. }=10 \\
\end{array}$} & \multicolumn{2}{|c|}{$\begin{array}{c}\text { SBP } \\
\text { No. }=38\end{array}$} & \multicolumn{2}{|c|}{$\begin{array}{c}\text { SFP } \\
\text { No. }=12\end{array}$} & \multirow{2}{*}{$\begin{array}{c}\text { Test of sig } \\
p \text { value }\end{array}$} \\
\hline & & $\mathrm{N}$ & $\%$ & $\mathrm{~N}$ & $\%$ & $\mathrm{~N}$ & $\%$ & \\
\hline \multirow{2}{*}{ Child score } & B & 2 & $20.0 \%$ & 1 & $2.6 \%$ & 0 & $0.0 \%$ & \multirow{2}{*}{0.095} \\
\hline & $\mathrm{C}$ & 8 & $80.0 \%$ & 37 & $97.4 \%$ & 12 & $100.0 \%$ & \\
\hline \multirow{2}{*}{ Death } & No & 8 & $80.0 \%$ & 22 & $57.9 \%$ & 3 & $25.0 \%$ & \multirow{2}{*}{0.030} \\
\hline & Yes & 2 & $20.0 \%$ & 16 & $42.1 \%$ & 9 & $75.0 \%$ & \\
\hline \multirow{2}{*}{$\mathrm{HCC}$} & No & 8 & $80.0 \%$ & 27 & $71.1 \%$ & 4 & $33.3 \%$ & \multirow{2}{*}{0.041} \\
\hline & Yes & 2 & $20.0 \%$ & 11 & $28.9 \%$ & 8 & $66.7 \%$ & \\
\hline
\end{tabular}

The mean meld score was significantly higher among the non survivors (27.6 \pm 4.0) versus survivors $(19.2 \pm 3.3)$, the duration of ESLD per years was also significantly higher in non survivors $(5.7 \pm$ 2) versus in survivors $(4.1 \pm 1.5)$ (Table 3). 
Table (3): Comparison regarding to the mortality rate between SBP and SFP based on MELD score and duration of ESLD

\begin{tabular}{|c|c|c|c|c|c|}
\hline \multirow{2}{*}{ Garameters } & \multicolumn{2}{|c|}{$\begin{array}{c}\text { Survivors } \\
\text { No. }=33\end{array}$} & \multicolumn{2}{c|}{$\begin{array}{c}\text { Non survivors } \\
\text { No. }=27\end{array}$} & \\
\cline { 2 - 6 } & Mean & SD & Mean & SD & p value \\
\hline MELD & 19.2 & 3.3 & 27.6 & 4.0 & $<0.001$ \\
\hline Duration of ESLD (years) & 4.1 & 1.5 & 5.7 & 2.0 & 0.004 \\
\hline
\end{tabular}

There was no significant difference between the survivors and non survivors regarding to the Child score, but there were significant differences regarding the mortality rate in patients with $\mathrm{HCC}(88.2$ $\%$ ) (This table displays the odds ratios 17.25) Table (4).

Table (4) Logistic Regression analysis between survivors and non survivors regarding to Child score and presence of $\mathrm{HCC}$

\begin{tabular}{|c|c|c|c|c|c|c|c|}
\hline \multicolumn{2}{|c|}{ Groups } & \multicolumn{2}{|c|}{ Survivors } & \multicolumn{2}{c|}{ Non survivors } & Fisher exact test & \multirow{2}{*}{ OR (95\%CI) } \\
\cline { 2 - 6 } Parameters & $\mathrm{N}$ & $\%$ & $\mathrm{~N}$ & $\%$ & $\mathrm{p}$ value & \\
\cline { 1 - 6 } Child score & $\mathrm{B}$ & 1 & $100.0 \%$ & 0 & $0.0 \%$ & \multirow{2}{*}{1.000} & \\
\cline { 2 - 6 } & $\mathrm{C}$ & 24 & $49.0 \%$ & 25 & $51.0 \%$ & & \\
\hline \multirow{2}{*}{ HCC } & No & 23 & $69.7 \%$ & 10 & $30.3 \%$ & \multirow{2}{*}{$<0.001$} & \multirow{2}{*}{$17.25(3.31-89.97)$} \\
\cline { 2 - 6 } & Yes & 2 & $11.8 \%$ & 15 & $88.2 \%$ & & \\
\hline
\end{tabular}

The mean value of leucocytic count, INR, blood urea and creatinine, potassium level and serum bilirubin was a significant variable in prognosis of patients with peritonitis regarding to mortality rate (Table 5).

Table (5): Comparison regarding to the mortality rate between SBP and SFP based on laboratory findings

\begin{tabular}{|l|c|c|c|c|c|}
\hline \multirow{2}{*}{ Parameters } & \multicolumn{2}{|c|}{ Survivors } & \multicolumn{2}{c|}{ Non survivors } & \multirow{2}{*}{ p value } \\
\cline { 2 - 5 } & Mean & SD & Mean & SD & \\
\hline $\mathrm{Hb}(\mathrm{gm} / \mathrm{dL})$ & 9.8 & 1.5 & 9.3 & 1.9 & 0.271 \\
\hline $\mathrm{WBC}\left(\mathrm{x} 10^{3} / \mathrm{mL}\right)$ & 9.0 & 4.3 & 13.3 & 7.9 & 0.022 \\
\hline $\mathrm{PLT}\left(\mathrm{x} 10^{3} / \mathrm{mL}\right)$ & 92.0 & 20.8 & 81.9 & 54.9 & 0.397 \\
\hline $\mathrm{INR}$ & 1.5 & 0.2 & 1.9 & 0.5 & 0.002 \\
\hline Urea $(\mathrm{mg} / \mathrm{dL})$ & 65.4 & 34.5 & 97.0 & 45.4 & 0.008 \\
\hline Creatinine $(\mathrm{mg} / \mathrm{dL})$ & 1.4 & 0.5 & 2.6 & 1.1 & $<0.001$ \\
\hline $\mathrm{Na}(\mathrm{mmol} / \mathrm{L})$ & 134.8 & 6.5 & 135.4 & 9.3 & 0.806 \\
\hline $\mathrm{K}(\mathrm{mmol} / \mathrm{L})$ & 4.2 & 0.5 & 4.6 & 0.6 & 0.008 \\
\hline ALT $(\mathrm{IU} / \mathrm{L})$ & 25.0 & 9.6 & 31.0 & 8.1 & 0.763 \\
\hline AST (IU/L) & 40.0 & 11.4 & 37.0 & 10.8 & 0.793 \\
\hline Albumin $(\mathrm{gm} / \mathrm{dL})$ & 2.5 & 0.3 & 2.3 & 0.6 & 0.137 \\
\hline Total bilirubin $(\mathrm{mg} / \mathrm{dL})$ & 2.0 & 0.6 & 2.8 & 1.0 & 0.001 \\
\hline
\end{tabular}

There was a positive correlation between the occurrence of SFP and and prolonged INR and long duration of ESLD $r=0.6$ (Fig. 1). 


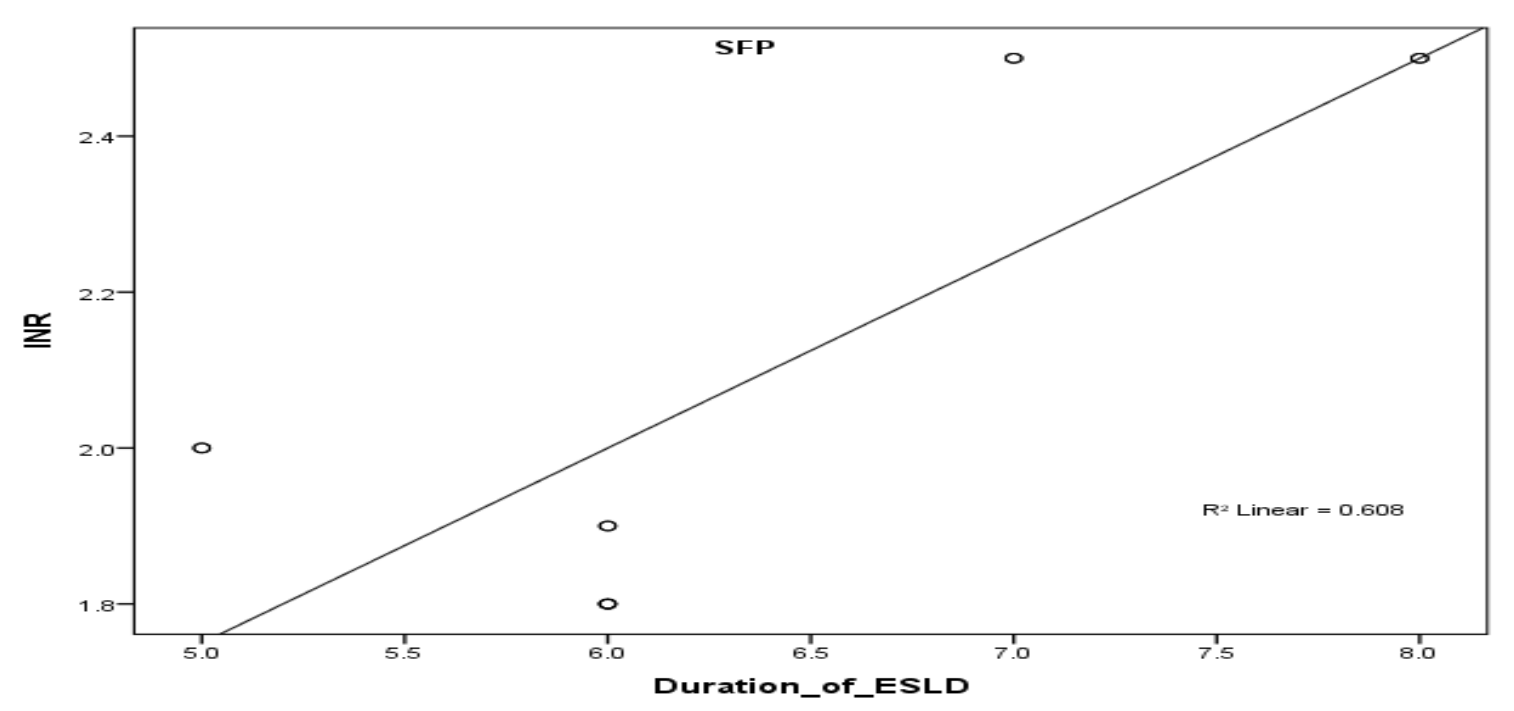

Figure (1): Correlation between the duration of ESLD, INR and occurrence of SFP

There was a positive correlation increased MELD score $r=0.3$ (Fig. 2). between the occurrence of SFP and

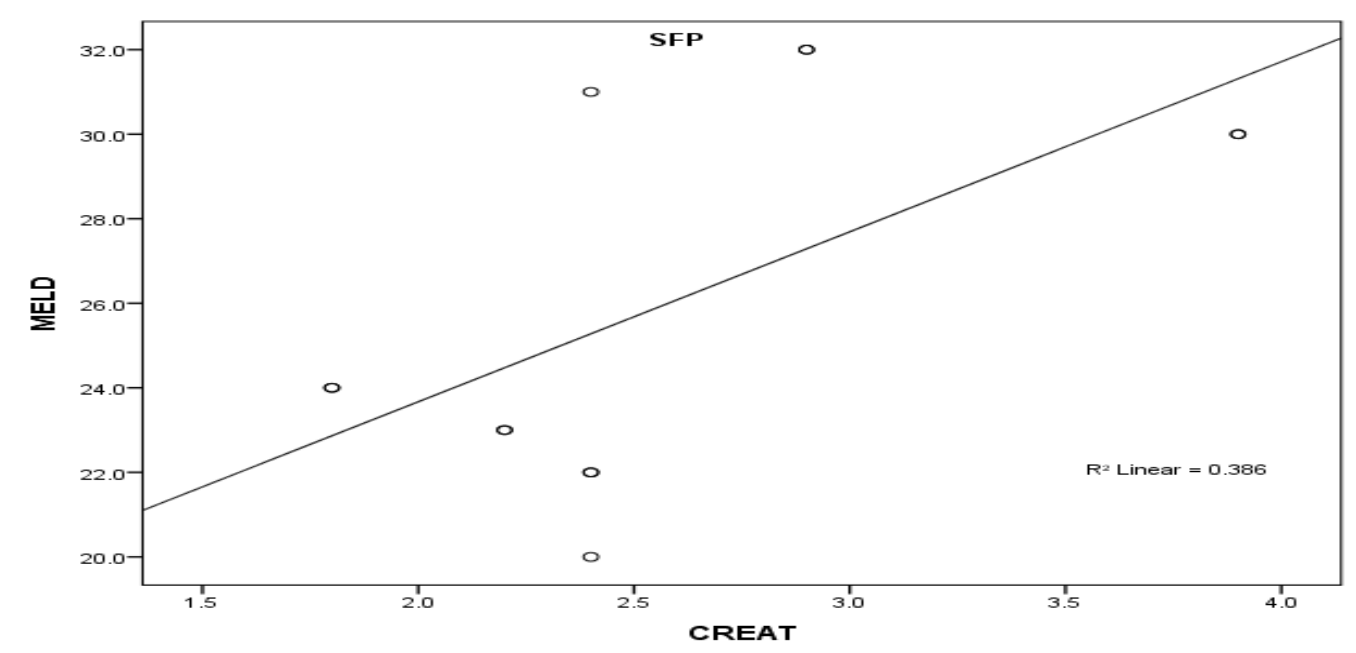

Figure (2): Correlation between MELD score and occurrence of SFP

\section{DISCUSSION}

The relationship between immune dysfunction and infection in cirrhosis, known as cirrhosis-associated immune dysfunction syndrome (CAIDS), has been investigated extensively. This syndrome is a multifactorial state of dysimmunoregulation, which is comprised of a reduction in serum bactericidal activity, opsonic activity, and complement and fibronectin levels (Bonnel et al., 2011).

The current work was one of few studies aiming to report the clinical character, risk factors, and prognosis of cirrhotic patients with fungal peritonitis compared to bacterial peritonitis.

Out of the total 50 cases of cirrhotic ascites, $75 \%$ were males and $25 \%$ were females. This high male to female ratio 
was due to the criteria of selection of patients at the beginning of the study. The incidence of bacterial and fungal peritonitis in the current study was $63.3 \%$ and $20 \%$ respectively. That disagreed with Hwang et al. (2014) who reported the incidence of SFP was $3.6 \%$ in Korean tertiary care center and also with Hassan et al. (2014) who reported the incidence of SFP in Egyptian population was $4.3 \%$, which may be due to the excessive use of prophylactic antibiotics in our selected patients.

Upper GI bleeding was evident in all patients with SFP and significantly increased compared to SBP and control group. This result agreed with de Mattos et al. (2014) who stated that the gastrointestinal bleeding is a predictor of incidence of SBP. Also, Hassan et al. (2014) stated that fungal translocation may be facilitated by upper gastrointestinal bleeding, which is also common in patients with advanced liver cirrhosis.

High serum bilirubin, s.creatinin and low serum albumin and hyponatremia was a significant risk factors among the studied groups the results is matched with the report of Fernandez et al. (2016) that the presence of low ascitic protein concentration $(<1.5 \mathrm{~g} / \mathrm{dL})$ when combined with any of the following characteristics: Child-Pugh score $\geq 9$, serum bilirubin level $\geq 3 \mathrm{mg} / \mathrm{dL}$, impaired renal function (creatinine $\geq 1.2 \mathrm{mg} / \mathrm{dL}$ or blood urea nitrogen level $\geq 25 \mathrm{mg} / \mathrm{dL}$ ), or hyponatremia $(\leq 130 \mathrm{mEq} / \mathrm{L})$ are a recognized risk factors in spontaneous peritonitis (Fernandez et al., 2016).

Another recognized risk factor for spontaneous peritonitis in the current study was higher child score among the studied group (95\%) were child C, and (5\%) were child B. All SFP patients were Child $\mathrm{C}$ and $37 / 38$ (97.4\%) of SBP group were child $\mathrm{C}$ and $80 \%$ of control group were child $\mathrm{C}$ the finding that explain that the severity of liver impairment was associated with spontaneous bacterial and fungal peritonitis. These results agreed with Fiore et al. (2016) who reported that patients with cirrhosis are at an increased risk of fungal infections, and with Hwang et al. (2014) who analyzed the clinical characteristics and the prognosis of patients with spontaneous peritonitis, $3.6 \%$ of whom presented spontaneous fungal peritonitis. In those patients, the most frequent isolate was Candida albicans, followed by Candida glabrata, Candida krusei, Cryptococcus spp., and Aspergillus spp.

High MELD score was an additional recognized risk factor in the occurrence of spontaneous bacterial and fungal peritonitis among the studied groups. The mean MELD score was significantly increased in SFP than SBP and control group. The result matched with the study of Rashid et al. (2019) who stated that patients and control SBP was 11\%, 31\%, $71 \%$, and $93 \%$ at baseline MELD scores less than or equal to 10 , from 11 to 20 , from 21 to 30, and greater than 30, respectively. Compared with MELD score less than or equal to 10 , patients with MELD scores were from 11 to 20,21 to 30 , and greater than 30 had six folds $(95 \%$ CI) risk of SBP (Rashid et al., 2019).

High Child-Pugh or MELD scores increased the risk of SFP in patients with liver cirrhosis. A retrospective casecontrol study by Gravito-Soares et al. 
(2017) found no significant difference in the Child-Pugh or MELD scores of patients with SFP and SBP.

The mean duration of ICU admission was significantly higher in patients with SFP compared to SBP and control group. This agreed with Gravito-Soares et al. (2017) who reported that the long duration of hospital admission is a risk factor for SFP occurrence.

The overall mortality in the current study was $45 \%$. The highest mortality was among the SFP group than in SBP and control group (75\%, 42.1\% and 20\% respectively).Predictors of mortality in SFP and SBP include severe underlying liver disease with a high Child- Pugh or MELD score, renal impairment such as HRS, and onset of severe sepsis. Our results were in concordance with that reported by Bal et al. (2016) who reported that the predictors of mortality in SBP was the same factors reported in our study. Other predictors of SFP and SBP mortality in the current study included prolonged admission in the IC unit, other comorbidities, GI bleeding, rapid deterioration of liver function, positive ascitic fluid fugal culture, elevated blood leukocyte level, and presence of HCC. Tandon et al. (2011) reported that peripheral blood leukocyte count $\geq 11 \times$ 109 cells/L and MELD score $\geq 22$ were independent predictors of 30-d mortality in patients with liver cirrhosis and SBP.

SFP mortality is estimated to be $56 \%$ 90\% in multiple studies (Hassan et al., 2013, Bremmer et al., 2015 and Gravito et al., 2017), and 1-mo mortality may or may not be significantly higher than SBP mortality. Hwang et al. (2014) reported a high SFP mortality that was related to unresponsiveness to initial empirical treatment for suspected SBP. The condition of nearly all the patients with SFP worsened after initial empirical treatment, and they died during the early stage of peritonitis regardless of undergoing antifungal treatment. Some patients with SFP improved after receiving the initial empirical treatment without any antifungal agents. Those patients may have had SBP and colonization by innocent fungi, as it was not possible to distinguish fungal colonization from true SFP in the clinical setting. SFP is usually diagnosed after the identification of fungi in cultures of ascitic fluid. The mortality was high because of delayed diagnosis, lack of clinical signs, lack of suspicion of SFP, and delay in treatment with antifungal therapy. Fungal resistance to empirical specific antifungal therapy together with delayed diagnosis and treatment is related to poor prognosis of SFP (Gravito et al., 2017).

The highest incidence of mortality in SFP group (75\%) may also due to delayed diagnosis, lack of clinical signs specific to SFP, lack of suspicion and delay in treatment with antifungal therapy as that is reported by Gravito et al.(2017).

\section{CONCLUSION}

SFP is not a rare complication in end stage liver disease. SFP is underrated and associated with increased mortality rate as compared to SBP. Physicians should be aware of SFP in patients with CHILD C liver cirrhosis, elevated MELD score, antibiotic pretreatment and nosocomial peritonitis. SFP is an important complication of cirrhosis that is associated with high rates of death. Hence, to improve the outcome in these patients, 
clinicians should have a high index of suspicion for this lethal entity so that it may be detected early, and empiric antifungal treatment should be started, especially in high-risk patients, until appropriate treatment can be used.

\section{REFERENCES}

1. Albillos A, Lario $M$ and Álvarez-Mon $M$. (2014): Cirrhosis-associated immune dysfunction: distinctive features and clinical relevance. J Hepatol., 61: 1385-1396.

2. Bal CK, Daman $R$ and Bhatia V. (2016): Predictors of fifty days in-hospital mortality in decompensated cirrhosis patients with spontaneous bacterial peritonitis. World $\mathbf{J}$ Hepatol., 8: 566-572.

3. Bellot P, Francés $R$ and Such J. (2013): Pathological bacterial translocation in cirrhosis: pathophysiology, diagnosis and clinical implications. Liver Int., 33: 31-39.

4. Bonnel AR, Bunchorntavakul C and Reddy KR (2011): Immune dysfunction and infections in patients with cirrhosis. Clin Gastroenterol Hepatol., 9:727-38.

5. Bremmer DN, Garavaglia JM and Shields RK (2015): Spontaneous fungal peritonitis: a devastating complication of cirrhosis. Mycoses, 58: 387-393.

6. De Mattos AA, Costabeber AM, Lionço LC and Tovo CV (2014): Multiresistant bacteria in spontaneous bacterial peritonitis: a new step in management? World J Gastroenterol., 20: 14079-14086.

7. Fernandez $J$, Tandon $\mathbf{P}$, Mensa $J$ and Garcia-Tsao G (2016): Antibiotic prophylaxis in cirrhosis: good and bad. Hepatology, 63(6):2019-2031.
8. Fiore $M$ and Leone $S$ (2016): Spontaneous fungal peritonitis: Epidemiology, current evidence and future prospective. World J Gastroenterol., 22: 7742-7747.

9. Gravito-Soares M, Gravito-Soares E, Lopes S, Ribeiro $G$ and Figueiredo $P$ (2017): Spontaneous fungal peritonitis: a rare but severe complication of liver cirrhosis. Eur $\mathbf{J}$ Gastroenterol Hepatol., 29: 1010-1016.

10. Hassan EA, Abd El-Rehim AS, Hassany SM, Ahmed AO, Elsherbiny NM and Mohammed MH (2014): Fungal infection in patients with end-stage liver disease: low frequency or low index of suspicion. Int $\mathbf{J}$ Infect Dis., 23: 69-74.

11. Hwang SY, Yu SJ, Lee JH, Kim JS, Yoon JW, Kim YJ, Yoon JH, Kim EC and Lee HS (2014): Spontaneous fungal peritonitis: a severe complication in patients with advanced liver cirrhosis. Eur $\mathrm{J}$ Clin Microbiol Infect Dis., 33: 259-264.

12. Khan $\mathbf{R}$, Ravi $\mathbf{S}$ and Chirapongsathorn $\mathbf{S}$ (2019): Model for End-Stage Liver Disease Score Predicts Development of First Episode of Spontaneous Bacterial Peritonitis in Patients with Cirrhosis. Mayo Clinic proceedings, 94 (9): 1799-1806.

13. Shizuma T (2018): Retrospective Comparative Study of Spontaneous Peritonitis Associated with Fungal and Bacterial Infection in Patients with Liver ICirrhosis $\mathrm{J}$ Liver, 7:1-3.

14. Tandon $P$ and Garcia-Tsao G (2011): Renal dysfunction is the most important independent predictor of mortality in cirrhotic patients with spontaneous bacterial peritonitis. Clin Gastroenterol Hepatol., 9: 260-265. 
در اسة مقارنة بين الالتهاب البريتوني التلقائي الفطري

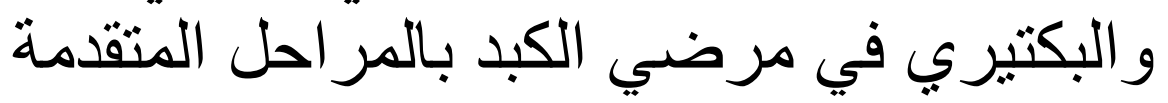

محمد النادري*، عبد الله هنداوى الشحات *، محمد أبو غبشة:**، عمرو جلال

قسمي الكب والجهاز الهضمي* و الباثولوجيا الاكلينيكية***، كلية الطب- جامعة الأزهر، القاهرة

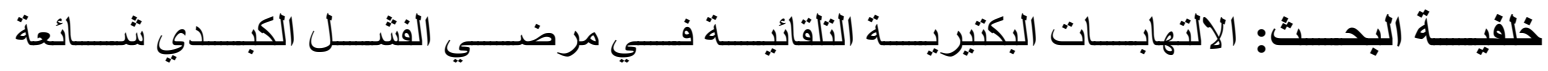

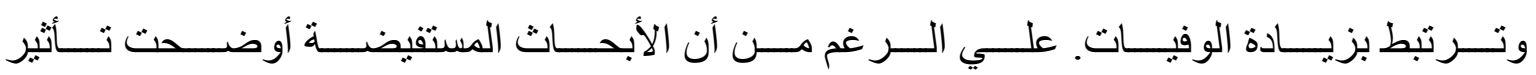

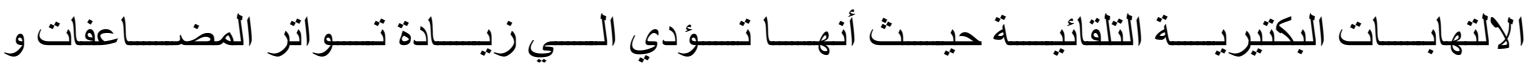

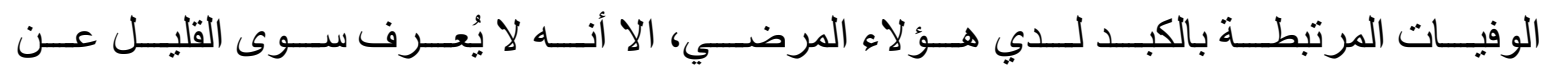
دور الالتهابات الفطريه التلقائية.

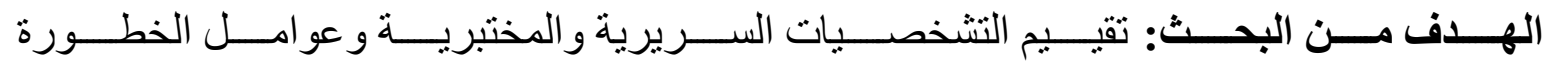

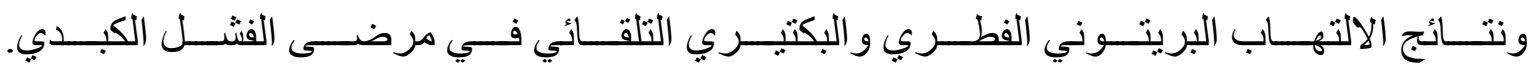

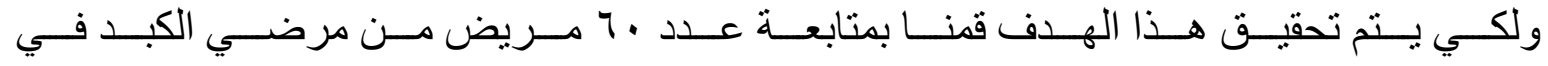

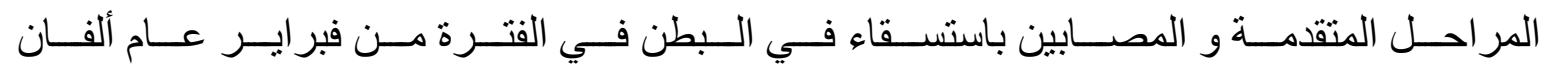

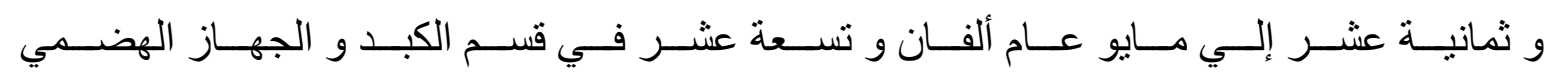
بكلية الطب جامعة الأز هر ومستشفي الهلال الأحمر.

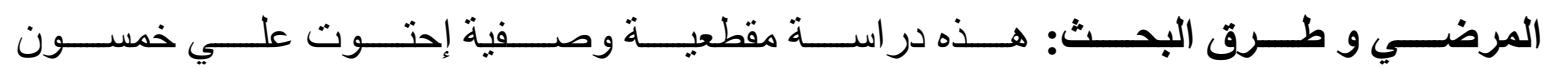

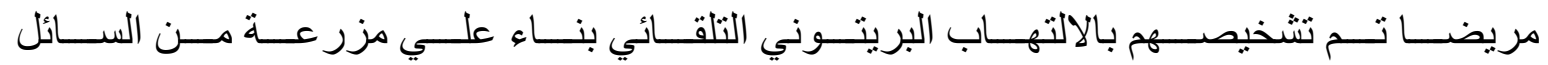

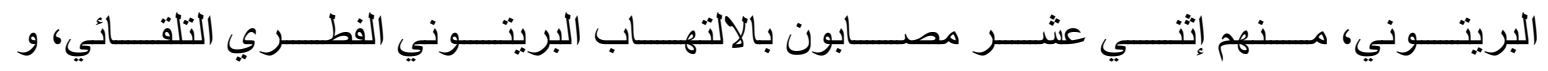

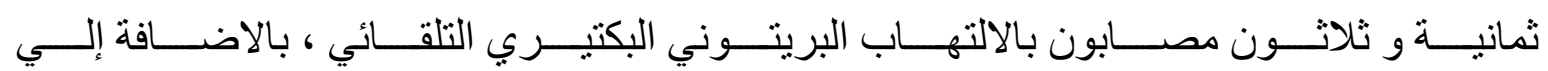

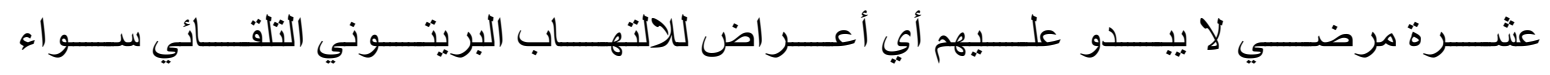

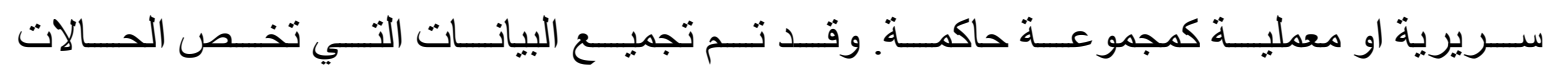

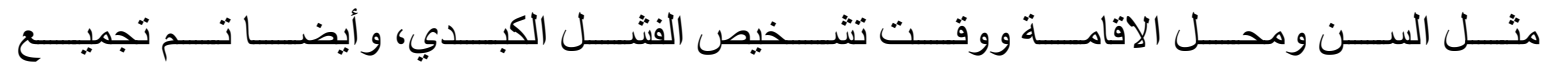

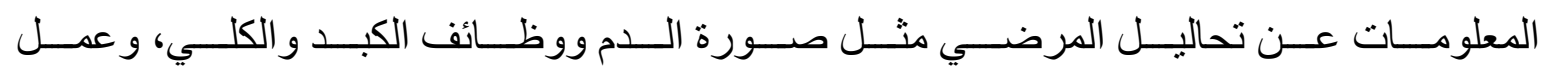

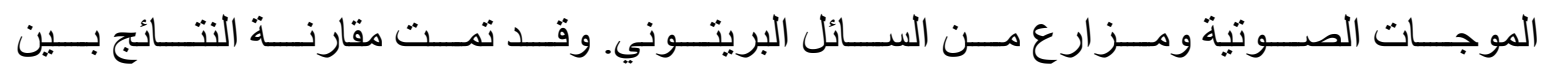

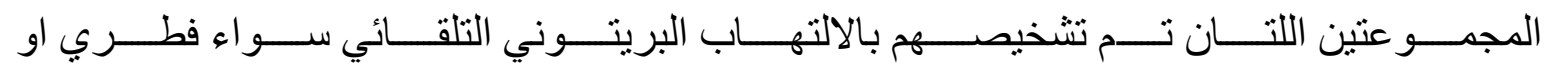




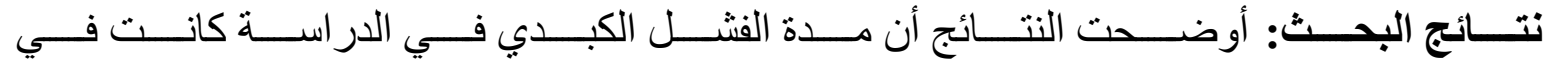

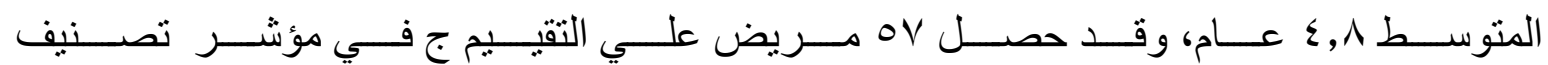

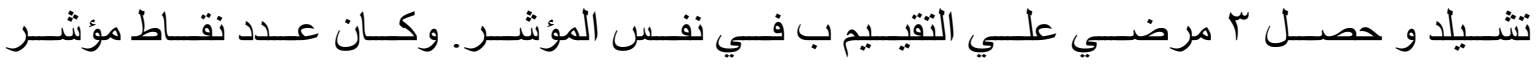

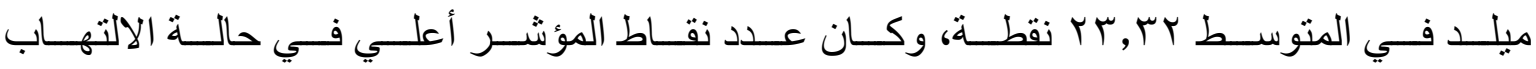

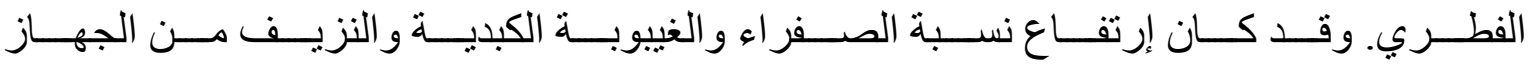

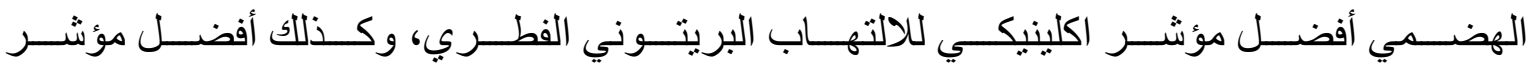

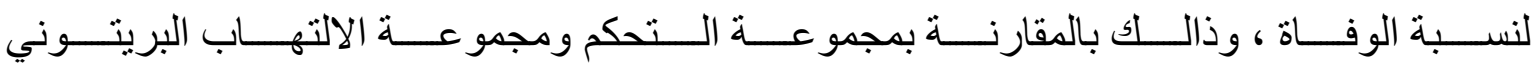
البكتيري.

وكــان انخفــاض نســبة الهيموجلــوبين و قلــة عــدد الصــفائح و ارتفــاع نســبة عــدد

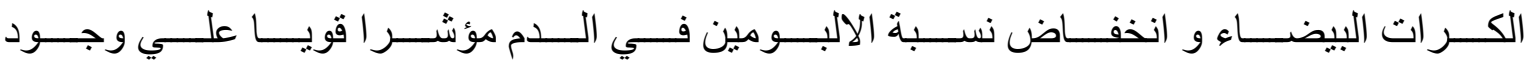

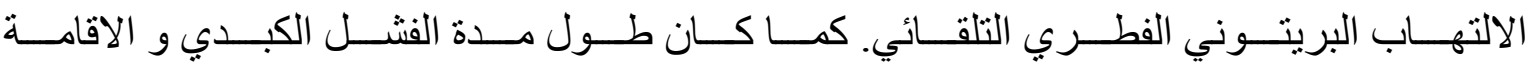
بالمستشفي أعلي في الالتهاب البريتوني الفطري التلقائي.

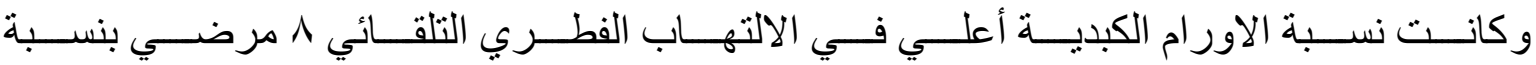

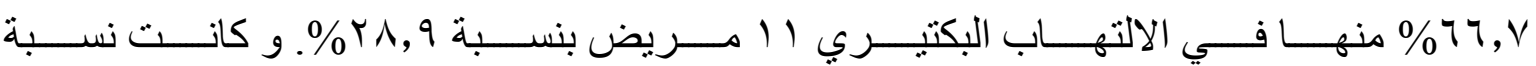

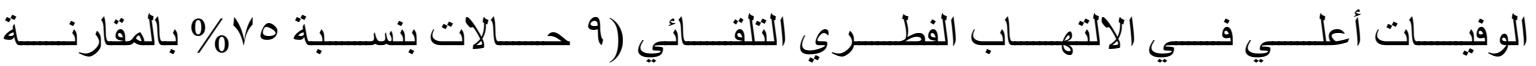

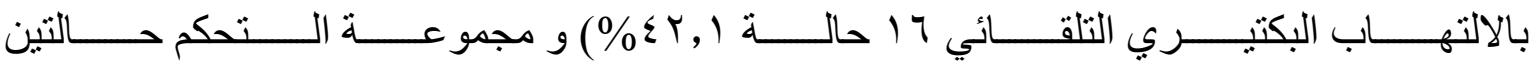

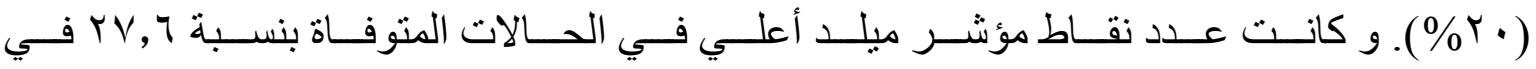

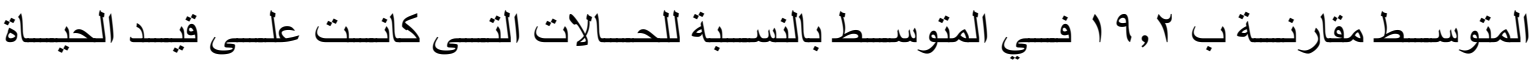

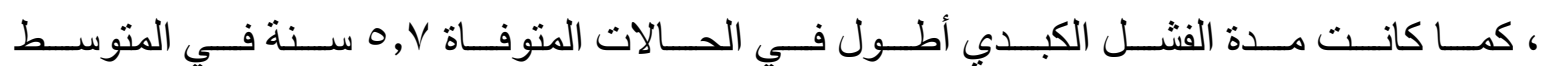
مقابل ا , ع سنة للباقي.

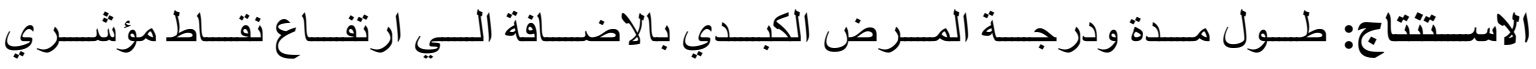

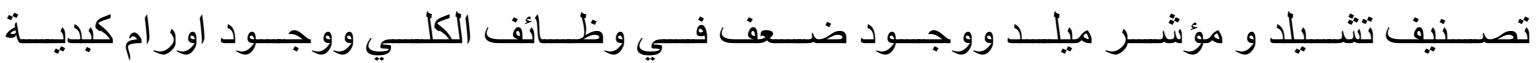

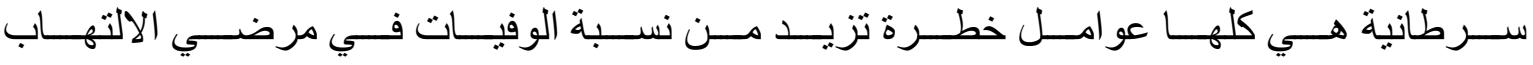

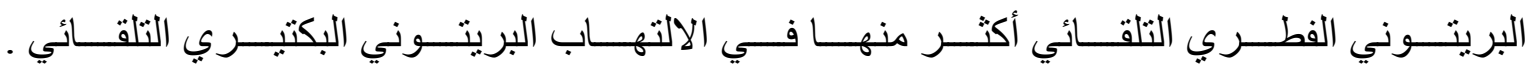

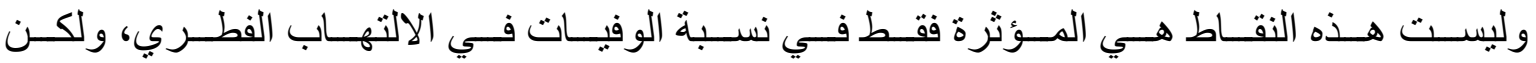

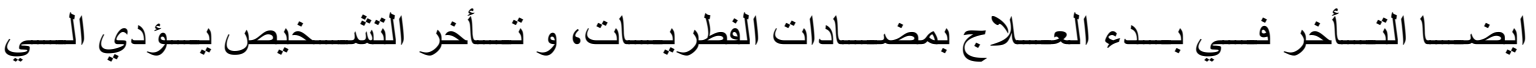
نتائج أسو أ. 